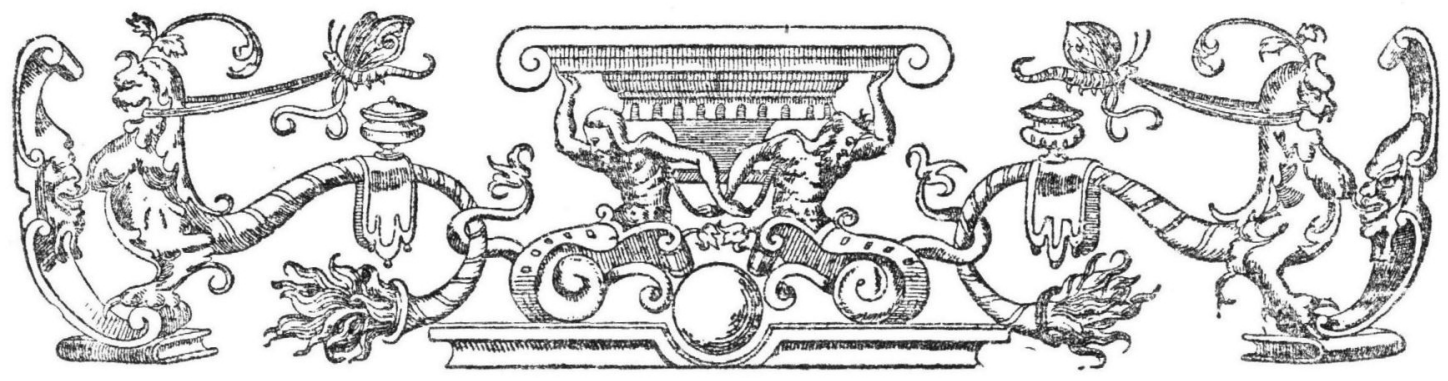

\title{
De Fontein op de Vischmarkt te Leiden.
}

DOOR

I M A BLOK.

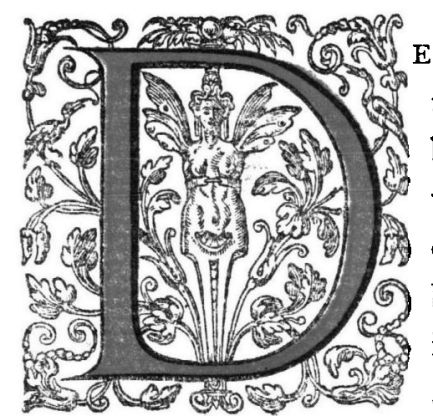

E stad Leiden bezit in de fontein op de Vischmarkt een monument uit het laatst der $I 7$ de eeuw, dat niet alleen belangrijk is, omdat het voorzag in de behoefte der vischkoopers aan zuiver water, maar ook, omdat de stad er buitengewoon door verfraaid werd. Om goed te begrijpen, wat de oprichting van deze fontein beteekent, is het noodig, dat we eerst de Leidsche gebouwen beschouwen, welke ontstonden in de vijftig jaren, die aan het oprichten van de fontein zijn voorafgegaan. Omstreeks $1650-60$ werden de belangrijkste gebouwen niet door de stad, maar door particulieren opgericht o.a. de Bibliotheca Thysiana door Thysius (1655); andere Leidsche burgers versierden op minder grootsche wijze de gebouwen, die ze lieten maken; o.a. door in den gevel hunner woningen gevelsteenen aan te brengen. Het bestuur der stad zelve liet in den eersten tijd nadat de Lakenhal en de Marekerk waren gereed gekornen slechts zeer weinig bouwen, de eenige gewichtige werken, die tot stand kwamen, waren de Witte Poort en de bijbouw van het Gerecht met een gedeelte der Loggia. Tegen 1660 echter ontstond de Waag, - gemaakt naar een ontwerp van PIETER POST en versierd met beeldbouwwerk door RoMBOUT VERHULST, - en het Pesthuis. Weldra volgden meerdere bouwwerken, allereerst de westelijke aanbouw aan het 
stadhuis met de burgemeesterskamers, dan een poort aan den Burcht, die RomBouT VERHULST met een leeuw versierde, in 1672 de groote voorbouw aan het Gerecht, waarvoor XAVERIJ het beeldbouwwerk maakte, en ook de toren van de academie. Nadat een uitbreiding der stad aan de kanten van de Heerengracht, het Plantsoen en Hoogewoerd had plaats gehad, werden aan de singels achtereenvolgens de Hoogewoerdspoort (I659), de Marepoort (1664), de Zylpoort (1667), de Morschpoort (1669) en tenslotte in 1682 de Heerenpoort opgericht. Met het bestuur der stad wedijverden particulieren door het bouwen van groote huizen met kolossaalpilasterorden, versierd met festoenen. In dien tijd (I68I) ontstond ook het Meermanshof, dat men zelfs den naam van ,Meermansburg” gaf.

Het beeldhouwwerk, dat aan de genoemde gebouwen uit de laatste veertig jaar der I 7 de eeuw voorkomt, is zóó uitgevoerd en aangebracht, dat het aan het geheel een schilderachtig effect geeft. Terwijl vroeger, zooals bijv. bij de Lakenhal het beeldbouwwerk vrije groepen vormt of als kleine platte reliefs ver van de pilasters is aangebracht en ook de versiering van het fronton ver van de lijst ligt - en er dus geen onmiddellijk verband is tusschen het beeldbouwwerk en het omringend architectonische gedeelte, is dit wel het geval bij gebouwen als het Gerecht, het Pesthuis en de Zijlpoort, waar de reliefs vast omsloten zijn door de architectonische deelen en de frontons geheel gevuld zijn. De reliefs aan die latere gebouwen springen ook veel meer naar voren dan aan die der vroegere, waardoor een sterke accentueering van licht en schaduw, een sterk schilderachtig effect verkregen wordt.

Uit nog een latere periode dateert de fontein op de Vischmarkt, zij werd tusschen 1690 en 92 opgericht. VAN MIERIS in zijn "Beschrijving der stad Leyden” 1) vertelt de geschiedenis van de markt, waarvan hier sprake is. De vischmarkt was beroemd om den grooten aanvoer van allerlei zeevisch en om den zalm, die er gedurende het geheele jaar verkocht werd. Reeds vóór 1376 was daar een Vischkapel opgericht, die echter in 1567 werd afgebroken.

In 1575 had er eene uitbreiding van de Vischmarkt plaats, vaN MIERIS spreekt van het aanleggen van "bekwaame banken en wallen mitsgaders lommerachtige plantagien". Zeker is het, dat de vischmarkt in de $I 6$ de en 17 de eeuw een tijd van grooten bloei beleefde. In de tweede helft der 17 de eeuw bleek het echter, zoo vertelt ons VAN MIERIS, dat het water vooral 's zomers niet meer geschikt was voor het frisch houden van de visch (het water namelijk dat in den Rijn stroomde). Zoo besloot het bestuur der stad op 17 Aug. 1690 na velerlei overwegingen, dat ten behoeve der vischkoopers het welwater uit den Burcht in looden buizen onder

1) 1762 deel I p. I59, 1770 deel II p. 528 vlg. 
den Rijn door naar de Vischmarkt zou worden geleid door middel van een paardemolen. "Tot dat eind wierdt weinig tijds hier naa vast gesteld nog een put op de Burg bij die van de eersten te doen schieten" 1). Er bleek overvloedig water te zijn, zoodat men voor afvoer moest zorgen. Zoo kwam men tot het oprichten van een fontein. "Toen het werk teneinde was gebracht" zegt vaN MIERIS „zag men een ruimen waterbak met verhevene zuil", dolfijnen, kinders en andere sieraden waren van marmer gehakt, de fontein wierp's morgens op bepaalde uren een massa water uit, ten dienste der vischkoopers, die alleen het gebruik vergund was, daar de toegang voor anderen door een ijzeren hek afgesloten was.

De fontein, die men nu nog op de Vischmarkt ziet, beantwoordt geheel aan de beschrijving, die VAN MIERIS er van geeft. Ze heeft den vorm van een vierzijdig prisma met één vlakken kant. De fontein is van blauwen steen met marmer versierd en bestaat uit een bassin met basement en een pijler met beeldhouwwerk, door van Mieris ,een verhevene zuil" genoemd. Het bassin heeft den vorm van een rechthoek met verkropte hocken. De voorwand vertoont binnen blauwsteenen randen een langwerpige, marmeren plaat met schubornament. De verkropte hoekpilasters zijn met omgekeerde consoles van blauwen steen, die eveneens schubornament en tevens marmeren maskers dragen, getooid. De maskers zijn als ,,spuwers', voor het overtollige water uit het bassin behandeld, dat door hun breede monden in geschulpte bekkens, die op de verkropte trede van het basement geplaatst zijn, kan afgevoerd worden. Het tritontype der maskers met hun kromme neuzen en opgetrokken wenkbrauwen en het middelste deel der bovenlip vrijlatende snorren is duidelijk kenbaar aan het schelpvormig ornament op de voorhoofden en het riet inplaats van haren. Voluutvormige versieringen aan slapen, wangen en kin, doen het architectonisch karakter dezer siermotieven nog sterker uitkomen en sluiten zich op deze wijze aan bij de vormen van het bekken. Aan de zijwanden van het bassin bevindt zich hetzeifde schubornament als aan den voorwand. De borstwering bestaat uit een sterk geprofileerde lijst, het basement uit twee treden van steen, die denzelfden rechthoeksvorm hebben als het bassin. Op de bovenste plint bevinden zich de hierbovengenoemde bekkens.

In het midden van de lange achterzijde van het bassin verheft zich een vierkante pijler, welks wandplaten zoo geplaatst zijn, dat hunne achterkanten in de hoeken samenkomen, zoodat het geheel den indruk maakt alsof iedere zijde van het pijlerprisma met een dikke steenen plaat belegd was, waardoor aan de vier kanten hoekgleuven ontstaan. De voorzijde is versierd met een marmeren plaat met ijskegel of druipornament. Het basement van dien pijler bestaat uit

1) Volgens mededeeling van Mr. Dr. J. C. Overvoorde is kort geleden zulk een put op den Burcht teruggevonden. 
een rechte van boven hol geprofileerde plint, daaronder bevindt zich een nagenoeg vierkant voetstuk, dat in den achterwand van het bassin gemetseld is, doch zóó dat het aan voor- en achterkant door eenigen sprong zelfstandig blijft. Het kapitcel van dien pijler draagt een scherp gesneden architraaf en een breeduitstekend geprofileerde dekplaat.

Op plinten ter hoogte van de pijlerbasis, die rechts en links op de borstwering van den achterwand van het bassin rusten, liggen breede koppen van marmeren dolfijnen, wier schuin omhoogkronkelende lichamen en breede staartvinnen als levende siermotieven tegen den pijlerschacht aanliggen. Forsch behandelde waterplanten vullen de ruimte tusschen de kronkelende dieren en het architectonisch behandelde gedeelte; achter de dolfijnen liggen netten. Op het kapiteel van den pijler, slechts voor een klein deel erop rustend, bevinden zich vier bekkens in den vorm van schelpen, waarvan er twee gedragen worden door S-vormige, eenigszins week uitzwenkende met ijskegel of druipornament overstroomde consoles; deze consoles ontbreken aan voor- en achterkant, alleen het ijskegel-of druipornament is daar aanwezig. Te midden der vier schelpenbekkens verheffen zich op hunne vischstaarten twee kinkhoorn blazende, elkaar omstrengelende meerminnen, op wier met parelsnoeren getooide hoofden een schepenkroon rust als topversiering van het geheel. De achterzijde van de fontein, die naar de gracht toegekeerd is vertoont slechts twee met schubornament versierde vlakken. Onderaan bevindt zich, nog boven een gemetselde plint een gebeeldhouwd masker met cen bassin er onder voor de loozing van het water.

De waterverspreiding van de Leidsche fontein heeft plaats op twee verschillende hoogten, zooals een teekening van JAN DE BEYER van I759, (Afb. II), en de prent bij VAN MIERIS naar die teekening toonen, namelijk onderaan uit de twee neusgaten van ieder der dolfijnen, terwijl een hoogere straal in het midden vlak tegen den pijler aan omhoog springt, en bovenaan uit de schelpen, die de meerminnen vasthouden, ook hier ontspringt een hoogere straal in het midden van uit de schepenkroon.

$\mathrm{Bij}$ het oprichten van de fontein heeft men rekening gehouden met de omgeving, waarin ze kwam te staan, namelijk aan den waterkant van een gracht, gelegen tusschen twee bruggen. Met haar frontzijde is ze naar de Vischmarkt gekeerd en bovendien vlak tegenover de Stadhuispoort geplaatst. Het opzettelijke van deze plaats komt duidelijk uit in de teekening van G. LAMBERTS uit het begin der rge eeuw.

Te oordeelen naar de ornamentale versiering moet de fontein in het laatst der 17 e eeuw ontstaan zijn. De wijze, waarop de dikke doch platte, voluutachtige versieringen aan de maskers gevormd zijn, herinnert aan het laat Lodewijk XIVde type, ze zijn namelijk telkens verbonden door een klein recht gedeelte. Ze hebben 
niet meer de groote, rechte deelen, die in den Lod. XIVden stijl met bochtige vormen afwisselen en ze hebben nog niet de onmiddellijk aan elkaar opvolgende versiering met krullen enz. van later. Ook het ijskegel- of druipornament op de marmeren platen is een laat $\mathbf{I} 7 \mathrm{de}$ eeuwsch ornament. Dit eigenaardig barokornament wordt sedert het einde der $16 \mathrm{e}$ eeuw in Italië en Frankrijk gevonden, maar toegepast werd het vooral later, in de 2 de helft der $17 \mathrm{e}$ eeuw, het had den naam van "congélations", ijsstollingen.

Over den stijl van deze barokfontein valt ook verder nog wel een en ander te zeggen. De barokfonteinen zijn, zooals we weten, uit Italië aflionstig; de voornaamste zijn wel de beide fonteinen van LoRENzo BERNiNI: de Tritonfontein en die der Vier Stroomen te Rome. De vormen aan deze monumenten zijn week, ook het bekken heeft bochtige vormen. BERNINI's dolfijnen aan de Tritonfontein dragen werkelijk het bekken, de triton spant zich in den hoorn in den hoogte te houden, een sterk vertikale richting is in het geheele monument merkbaar. Zooals ons eveneens bekend is, namen de Franschen veel van den Italiaanschen barok over; de Fransche fontein, die hier belangrijk blijkt is de "fontaine des Pyramides" van GIRARDON uit 1672. Is er bij het werk van den Italiaan sprake van functies, bij den Franschman zijn het də proporties waar het omgaat. Het werk van den laatste is als een bouwwerk: dit is een opeenstapeling van abstracte vormen; deze vormen wisselen af met aan de natuur ontleende. GIRARDon's figuur bestaat uit een aantal horizontale naar boven toe kleiner wordende zones of verdiepingen, die aan een middenspil vastzitten. Het geheel heeft daardoor den vorm van een pyramide, waaraan de naam der fontein ontleend is. Onderaan bevinden zich tritons, ze maken een beweging alsof ze het bekken boven hen steunen, doch doen dit niet werkelijk, zooals men kan zien aan de houding hunner lichamen, waarvan slechts het bovenstuk omhoog gericht is, terwijl het vischachtige deel zwemmend is weergegeven en dus een horizontale richting heeft. Ook de meerminnen, een zone hooger, steunen het boven hen zich bevindende bekken niet, evenmin de op hun koppen rustende dolfijnen met stijve lichamen, die zich tusschen de beide zone's inschuiven. Als bekroning van het geheel, den top der pyramide vormend, is vlak boven den middenspil op de bovenste zone of verdieping een vaas aangebracht. Een tweede belangrijk verschil tusschen de Italiaansche barokfontein en de Fransche bestaat in de wijze, waarop het materiaal behandeld is; bij BERNINI zijn de profielen, etc. week en bochtig, bij de „fontaine des pyramides" zijn ze scherp en hard. Tenslotte hebben we te denken aan de wijze, waarop het water der fonteinen verspreid wordt, bij de Italiaansche fontein zijn het dikke stralen, bij de Fransche daarentegen stralen van weinig middellijn, zooals bij den geheelen stijl past. 
De stijl der Leidsche fontein toont zeer veel overeenkomst met de hierboven beschreven fontein van GIRARDON en ze heeft daarentegen zeer weinig van BERNINI's fontein. $\mathrm{Ze}$ is als het ware de Hollandsche vertaling van den stijl van Girardon, die zelf behoorde tot de groep, waarvan $\mathrm{CH}$. LEBRUN de voornaamste was. De verwantschap met het Fransche monument ligt in den piramideachtigen opbouw, het groote aantal architectonische deelen, hunne scherpe omtrekken vooral en de scherpe afscheiding van architectonische deelen en van aan de naturur ontleende vormen. Ook de manier, waarop het water omhoogspringt, nam. in een aantal dunne stralen, terwijl het midden van fontein en pijler geaccentueerd wordt door een hoogeren straal, is dezelfde als bij de Fransche fontein. Niet Fransch, maar Hollandsch is de wijze, waarop de marmeren versiering is aangebracht, zoowel wat de plaats als wat de uitvoering betreft. De marmeren versiering komt bij de Leidsche fontein voor als een van de omgeving door kleur en vorm zich afscheidend gedeelte op enkele bijzondere plaatsen: aan de voorkanten van het bassin, als maskers met bekkens er onder aan de verkropte hoeken, in den vorm van dolfijnen terweerszijden van den pijler en tenslotte als bekroning van het geheel in den groep van meerminnen op den pijler. Het grootste deel van de witte marmeren versiering bevindt zich dus aan de hoeken en bovenaan, dus daar waar het oog van den toeschouwer het meest opgericht moet zijn, helder steken de lichte dolfijnflanken en het rijke ornament in top tegen de omgeving af; dat is geheel anders dan bij de fontein van GIRARDON, waar het beeldhouwwerk zich tusschen de verdiepingen bevindt. Het beeldhouwwerk van de Leidsche fontein heeft in tegenstelling met de scherpe profielen der architectonische deelen weeke, volle vormen en is min of meer schilderachtig bedoeld, zooals men kan zien uit de wijze, waarop het riet om de dolfijnen, het lichaam der dieren en hun week knobbelige koppen zijn weergegeven, vooral heeft de groep bovenaan dit zachte modele.

Te oordeelen naar deze verschillen in de uitvoering van de architectonische deelen en het beeldhouwwerk, zou men reeds vermoeden, dat meer dan één persoon de fontein gemaakt heeft. MONTAGNE weet er ons allerlei van te vertellen in zijn album met Leidsche gezichten in 1859-60 uitgegeven, maar hij vertelt ons niet, waar hij zijn kennis vandaan had. In de rekeningen van den thesaurier extraordinaris van Leiden tusschen de jaren 1689 en 94 vond ik echter de rekeningen betreffende het monument. Tenslotte leidden al de gegevens te samen tot de volgende conclusies.

De bouwmeester van het geheel schijnt JACOBUS Romans geweest te zijn, Zijn agenda gedurende het maken van de fontein is bewaard gebleven, zij dateert van 17 Oct. 1692. Deze JасOB Romans was de architect der stad en voor zoover 
we kunnen nagaan dezelfde als de Hagenaar JACOB ROMANS, die voor de intocht van Willem III triomf bogen makkte, ook werkte aan het stadhuis van's-Hertogenbosch, $O p$ het Loo en zijn werkplaats had in den Haag. Niet alleen de naam van den architect, maar oot dis van den beeldhouwer kennen we. Het was JoHannes HANNAERT of HAUNAERT 1 ), iemand uit de omgeving van ROMANS en die sedert 1683 te 's Gravenhage woonde doch meermalen voor de stad Leiden heeft gewerkt zooals uit de rekeningen blijkt. Nadat op 17 Aug. 1690 het besluit tot het oprichten van de fontein was genomen en op I 3 Juli I69o(?) reeds door JoH. HaNNaERT een "aerden" model van de fontein was gemaakt, schijnt er weinig vooruitgang in den loop der zaken te zijn geweest. Op 23 Maart 169I werd besloten, dat zooveel blauwe steen van de fundamenten der Waardkerk gebruikt zou mogen worden als voor het bassin van de nieuwe fontein noodig was; om het bassin gelijk te maken zou de straat aan de huizenzijde wat verlaagd, aan de waterkant wat verhoogd worden. Nadat het model van de fontein op 22 Febr. 1692 beschilderd was - de ornamenten wit, het bassin blauw - hebben volgens VAN MIERIS, op den $5^{\text {den }}$ Mart ,die van den Gerechte" na een voorafgaande beschouwing van een model, aan de Burgemeesters verzocht en hen gemachtigd hoe eerder hoe liever het werk voor de fontein te besteeden. Kort daarop 16 Mei ontving Jorr. HannaEkT geld voor het brengen van het model van ,twee tritons, die de kroon van Neptunus dragen" van 's-Gravenhage naar Leiden. Van zeer veel belang is de rekening, die loopt over het jaar 1692 en die we daarom hier achter weergeven; $z i j$ is belangrijk ten eerste omdat we er uit hooren, dat HanNaERT de modellen voor de marmeren versieringen makte, maar ook wegens de beschrijving van die marmeren versieringen. JohANNFS HANNAERT leverde dus al de modellen van het beeldhouwwerk, hij zelve heeft ook de bovenste groep van de fontein uitgevoerd, want op 28 Maart 1693 ontving hij f 250.- op afbetaling van het "sierat boven op de fonteyn" door hem aangenomen voor $f 450$. Het grootste deel der uitvoering echter schijnt over gelaten te zijn aan een zekere CORnElis Minee; MONTAGNE deelt ons namelijk mede, dat de regeering het aanbod van CORNELIS MINEE aannam om voor f 1500 - behalve eenige stukken hard. steen 2) - een sierlijke fontein te bouwen. Tegen April I693 was de voltooing van de fontein bijna aan haar einde. Den 4 den April werd door een zekere DrijFHouT, een "sosenselijst" geplaatst onder de groep op de fontein en deze groep zelve door HannaERT en zijn knechts op 25 April daar bovenop gesteld. Zoo was

1) Deze HANNAERT maakte ook het grafmonument van Dr. SChrlliaker (gest. I699) in de Luthersche kerk te 's Gravenhage. Het gedenkteeken is echter niet meer in de kerk aanwezig; zooals Dr. H. E. vaN GeLDER mij mededeelde moet het voor pl, m. 50 jaar verdwenen zijn Afb. en beschr. bij DE RIEMER I p. 4I8. Zie ook die Haghe Jaarboek Igr3.

2) Ongetwijfeld de stukken hardsteen van de Waardkerk, waarvan hierboven sprake was.

Oud-Holland 1918. 
na bijna drie jaar de fontein gereed gekomen en werd ze, zooals MONTAGNE vertelt op I Mei 1693 voor het eerst in werking gebracht.

Welk een gewichtige gebeurtenis het oprichten van de fontein was, blijkt uit het feit, dat kort na de voltooiing een penning ter harer eere vervaardigd werd door den graveur J. Smeltzing, die daarvoor $f$ (50 ontving. ') In deze penning bezitlen we de oudste afbeelding van de fontein. Het monument wordt er op voorgesteld met de looden buizen, die het water naar de Vischmarkt leidden, in de verte zien we den Burcht. Naast dit deel der voorstelling bevindt zich de Leidsche Maagd, zittend op een stapel laken met den spiegel en slang als symbool der voorzichtigheid in de eene hand, de speer in de andere, verder een leeuw met een waterkruik, wat den Rijn moet voorstellen. De keerzijde bevat een inscriptie tevens de wapens der burgemeesters en vroedschapsleden. Behalve door deze penning wordt de oprichting van de fontein verheerlijkt door een gedicht van J. GROENENDYCK : „Defectus operis in extruendo Fonte Lugd. Batavo.

In den loop der tijden heeft de fontein, voor zoover we kunnen nagaan, slechts één verandering ondergaan en wel aan de achterzijde. De oudste prent, die we van het monument hebben, is die door ABR. Rademaker van $173 \mathrm{I}$. Hierop wordt de fontein van de achterzijde afgebeeld. Twee groote voluten bevinden zich op de plaats waar we tegenwoordig den achterkant van de dolfijnen en netten zien; de fontein staat op deze prent ook niet zoo dicht aan den waterkant als tegenwoordig, het hek loopt aan de achterzijde door en het gemetselde stuk met het masker ontbreekt. De verandering werd waarschijnlijk uitgevoerd, omdat het Rijnwater, dat men nog steeds scheen te gebruiken meer en meer ongeschilst bleek voor het frisch houden van de visch, De toestand, zooals die bij RADEMAKER is weergegeven, is ongeveer dezelfde, als we op de teekening van 1753 van JAN DE BEYER zien, (Afb. III). Ook daar staat de fontein een eind van het water af; we zien aan den achterkant een soort afloopje naar het water toe, het hek is ook op dezelfde wijze aangebracht als op RADEMAKER's prent. Daar de fontein bij DE BEYER half van opzijde is atgebeeld, kunnen we echter niet goed zien of hier wèl dan niet de voluten en het gemetselde stuk aanwezig zijn. Ook vinden we bij geen een schrijver iets over die voluten en de verdere verandering vermeld. Wanneer de verandering aan de achterzijde dus heeft plaats gehad, is niet met zekerheid te zeggen, in ieder geval vóór 1837 , want op de teekening uit dat jaar door W. GroENEwoud vinden we den tegenwoordigen toestand weergegeven.

Tenslotte nog iets over het hek, dat om de fontein heen staat. Oorspronkelijk was er een zeer eenvoudig hek, zooals de prenten en teekeningen

1) Afgeb. on beschreven bij G. VAN LooN: Nederlandsche Historiepenningen IV p. $9 \mathrm{r}_{\text {; }}$ zie ook van Mikris op. cit. De penning zelve bevindt zich in bet Stedelijk Museum te Leiden, 
toonen, waarschijnlijk hetzelfde hek, waarover van MIERIS in zijn beschrijving van de fontein reeds spreekt. Omstreeks 1859 werd het oude hek vervangen door het tegenwoordig gegotene met gothiseerende vormen, versierd met dolfijnen geslingerd om Neptunus-drietanden en met cen schelpvormig ornament. De reeds genoemde MontaGne, die tegen 1859 ons een beschrijving van de tontein geeft, zegt uitdrukkelijk dat in den tijd, warin hij schreef, het oude hek, dat vervallen was, werd vervangen door een ander, een gegoten - en op de litho, die bij de beschrijving is weergeven, ziet men dan ook het tegenwoordige hek afgebeeld. Bovendien is, volgens denzelfden schrijver, de geheele fontein tegelijkertijd in orde gebracht. Men vernieuwde een gedeelte, de hardsteenen vloer werd gelijkgemaakt en de gebroken stukken door nieuwe vervangen. Of er misschien ook vormen vernieuwd zijn? We weten het niet, maar te oordeelen naar het monument zelve is het niet waarschijnlijk.

Hiermee zijn we dan aan het einde der beschouwing over de Leidsche fontein gekomen. Men heeft in haar dus een zeer belangrijk monument te zien

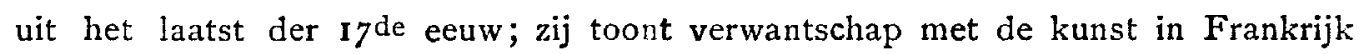
van $\mathrm{CH}_{\mathrm{H}}$. Lebrun en Girardor, werd hoogstwaarschijnlijk ontworpen door JACOB RoMANS, de modellen van het beeldhouwwerk werden geleverd door JoH. HANNAERT, die ook de voornaamste groep vervaardigde.

\section{B IJ L A G E.}

\section{REKENING UIT HET JAAR I692 VAN J. HANNAERT.}

Ten eersten gesneden twee spiegels an het petestell van het model tot de tontein met vier dropels daran verdient . . . . . . . . . . . . . . . . . . . . 2.0 noch gesneden twee groote schilpen van binnen eutgeholt ende angepast daran verdient 2.0 noch gesneden twee schilpen een vor en achter up het ornament daaran verdient 1.10 noch ter seyden twee dolfinen met liesbladen ende fisneten 6 gulden eyderverdient kompt. I2.0 noch gesneden een krone met twee sleutels verbelende het wapen van Leyden daran

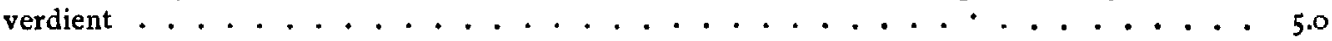
noch een model van was geposert an was arbeitslon, verdient noch 3 spiegels met fieschupen gesneden . . . . . . . . . . . . . . . . . . . 8.0 noch up de hurken op het bassin gesneden twe water baskese die water ontgeven met noch twee grote schilpen daran verdient. . . . . . . . . . . . . . . . . 4.0 noch gesneden een model van hout up twee Hande inve.... . daran verdient(?) . . 10.0 